\title{
Josh's Battery - a more even relationship with the grid $^{\star}$
}

\author{
Josh Byrne $^{1}$, Mark Taylor ${ }^{2, *}$, and Jemma Green ${ }^{3}$ \\ ${ }^{1}$ Curtin University Sustainability Policy Institute, Perth, Australia \\ ${ }^{2}$ Built Environment, Josh Byrne \& Associates, Fremantle, Australia \\ ${ }^{3}$ Curtin University Sustainability Policy Institute, Perth, Australia
}

Received: 8 February 2017 / Received in final form: 17 July 2017 / Accepted: 27 July 2017

\begin{abstract}
Josh's House is a "living laboratory" research and demonstration project in the Perth suburb of Hilton, Western Australia. The scope of Josh's House included the design and construction of two energy efficient family homes that achieved the highest level, 10-stars (estimated thermal load: $4 \mathrm{MJ} / \mathrm{m}^{2} /$ year) [Australian Government Department of Environment, Star rating scale overview, 2015 (Online), http://www.nathers.gov.au/owners-andbuilders/star-rating-scale-overview, accessed on: 2017/17/07], under the Nationwide House Energy Rating Scheme. The project partners include the Co-operative Research Centre for Low Carbon Living and Curtin University. In mid-2015, a further research component was added to Josh's House involving the installation and ongoing monitoring of a battery storage system. This system is a domestic example of a distributed energy storage system (DESS) and is here referred to "Josh's Battery" or "the DESS". The aim of the project is, in the first instance, to make domestic DESS data publicly available. Broader project objectives are to trial the technology, test assumptions on performance, document and communicate lessons and outcomes, and to inform further research and development. This paper provides an analysis of the monitoring data produced during the energy storage system's first year of operation. Particular areas of interest include: interaction with the electricity grid before and after installation of the storage system; correlation of system performance to specifications and modelled predictions; anomalies and unexpected results; and lessons learned from the installation and operation of the system. Implications and influences. The significance of this research is that it is built around the first monitored, grid connected domestic energy storage system in the Perth metropolitan area. It provides unprecedented data on how these systems can be expected to operate when embedded into a large-scale electricity network. The project also gives the opportunity to test some fundamental assumptions about these systems and feed into policy and business case development for the distributed energy storage sector, more broadly.
\end{abstract}

\section{Introduction}

While distributed energy storage systems (DESS) are heralded as an important enabler of renewable energy penetration into electricity networks globally [1-3], there are very few systems that have been installed in domestic situations that are being systematically monitored, analysed and the results published. The system that this study is based on is believed to be the first commercially supplied DESS on the South West Australian electricity grid (the South West Interconnected System, or SWIS) to be monitored and have its performance analysed and made publicly available through an independent study. What

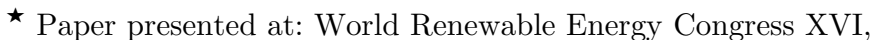
5-9 February 2017, Murdoch University, Western Australia.

* e-mail: mark@joshbyrne.com.au
}

makes the research even more unique is that the subject house represents the highest level of energy efficient design in the context of the Australian volume housing market.

Partners in the project are the Cooperative Research Centre for Low Carbon Living, Curtin University, and Josh Byrne \& Associates, as well as Solar Balance and the Western Australian Housing Authority. The involvement of these partners ensures that research outcomes are both robust and industry relevant.

\subsection{System overview}

Josh's House energy systems include:

- Photovoltaic (PV) system: $3 \mathrm{kWp} \mathrm{(kilowatt} \mathrm{peak,}$ indicating the nominal system size), grid connected through a 2.5 kilowatt $(\mathrm{kW})$ inverter;

- DESS: $8 \mathrm{kWh}$ energy storage unit based on lithium-ironphosphate battery chemistry. This is a BYD branded system, installed by the Australian distributor, Solar Balance; 
Table 1. Josh's House monitoring system (electricity related metering points).

\begin{tabular}{lll}
\hline Metered quantity & Units & Comment \\
\hline Total grid (import/export) & Watts $(\mathrm{W})$ & $\begin{array}{l}\text { Netted 3-phase imports from and exports } \\
\text { to the grid (data output from DESS) }\end{array}$ \\
Total load & $\mathrm{W}$ & Netted 3-phase loads (data output from DESS) \\
Total PV production & $\mathrm{W}$ & Feed from inverter (data output from DESS) \\
Battery state of charge & $\%$ & Data output from DESS \\
Battery power & W & Power flow in and out of DESS (data output from DESS) \\
GPO-1 & Watt hours (Wh) & Energy meter \\
GPO-2 & Wh & Energy meter \\
GPO-3 & Wh & Energy meter \\
GPO-4 & Wh & Energy meter \\
Oven & Wh & Energy meter \\
Lighting-1 & Wh & Energy meter \\
Lighting-2 & Wh & Energy meter \\
Rainwater pump \& UV lamp & Wh & Energy meter \\
Bore pump & Wh & Energy meter \\
Grey water pump & Wh & Energy meter \\
\hline
\end{tabular}

- Monitoring system: hard wired sensors and meters connected to a Datataker DT80 data logger;

- Hot water: gas boosted solar hot water system;

- Cooking: gas cooktop with electric oven.

\section{Methodology}

\subsection{Data collection}

Josh's House data are gathered from the various sensors and meters by a data logger and uploaded every 10 min to a cloud based storage and sharing site. The electricity metering points are listed in Table 1.

A small number of missing records (11 of 52704 row entries) were identified over the study year, 2016. These were replaced with synthesised entries using linear interpolation between last and next known values.

Units in use in the paper are:

- Energy metered: kilowatt-hour (kWh);

- Power metered: kilowatt (kW);

- PV array size: kilowatt-peak $(\mathrm{kWp})$ [the rated output at test conditions].

\section{Results}

\subsection{Load profile}

Load profile: Although the overall energy performance of Josh's House means that it uses far less energy than a typical Australian house at approximately $8 \mathrm{kWh} /$ day compared to $20 \mathrm{kWh} /$ day [4-6], the pattern of usage is not atypical. Featuring a morning peak and a larger afternoonevening peak, this is the expected pattern (known as the "double-hump") for a suburban family home with school age children and one or both parents working away from the home [7]. The load peaks in the case of Josh's House are less pronounced than for a typical Australian home that would have an air-conditioning load adding to the late afternoon peak. Figure 1 shows a comparison.

\subsection{Grid reliance}

The intention of Josh's Battery is to capture excess solar generation that is not required to meet household loads, and to store this energy to meet loads when solar generation is not sufficient. It is expected that the need to import electricity from the grid will be reduced to the times that the solar system cannot meet the load and the energy storage battery is depleted. The remaining dependence on importing electricity from the grid is here referred to as grid reliance. An inverse term is often used for this metric: grid defection, meaning the reduction in reliance on energy imported from the grid to meet loads. Table 2 illustrates the change in both metrics with the introduction of the PV system, and then the DESS. The table also presents the change on the PV baseline to illustrate the benefit of adding the DESS to an existing PV system.

There are other aspects of reliance on the grid that should be considered. Generally, grid tied PV inverter systems cannot operate without a grid signal, so that if the house is disconnected from the network, or there is a blackout, they would shut down. In the case of the DESS, Josh's Battery is capable of operating in UPS mode (uninterruptable power supply) to keep the home operating during a blackout for as long as the battery can supply energy. The Josh's House PV system continues to produce excess energy throughout the year, which is sold back into the grid based on an agreement with the electricity retailer that is common to all domestic PV systems on the SWIS. The tariff paid for electricity sold into the SWIS from Josh's House during 2016 was set in the Western Australian Renewable Energy Buyback Scheme (REBS). Table 3 illustrates the change in PV exports to the grid with the addition of the DESS. 


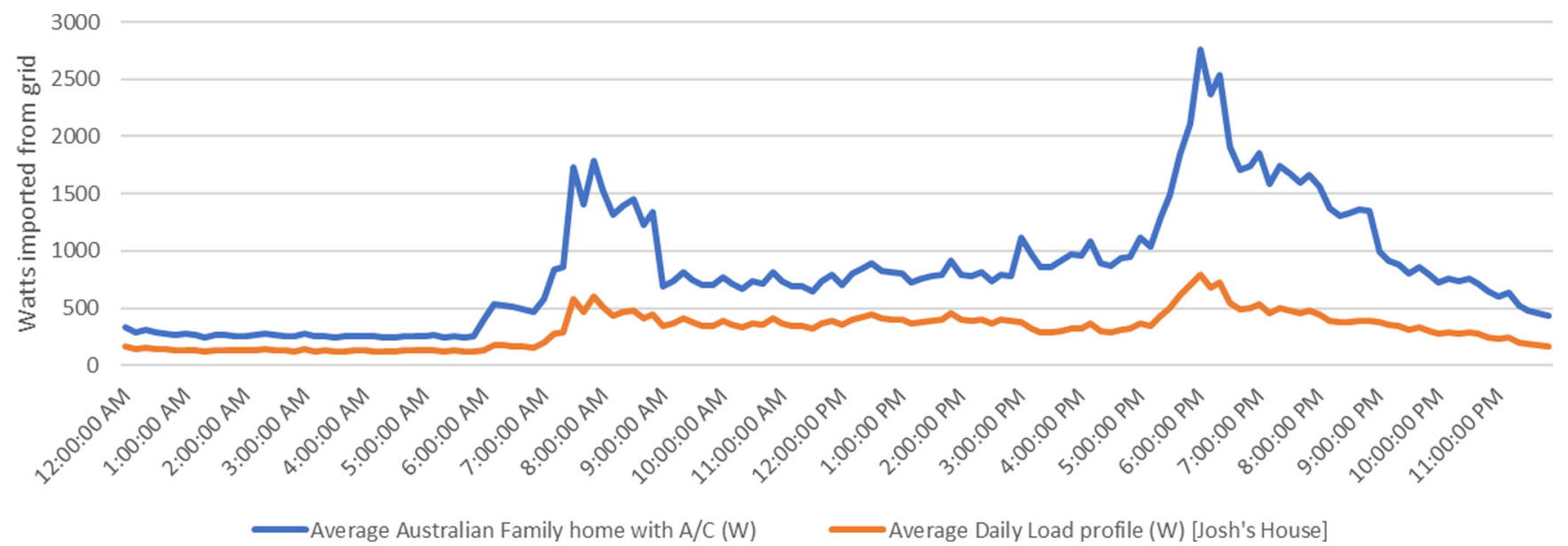

Fig. 1. Josh's House load profile (without PV or DESS) vs. typical Australian load profile.

Table 2. Josh's House grid reliance - impact of PV and DESS.

\begin{tabular}{lccclc}
\hline Grid reliance & $\mathrm{kWh} /$ year 2016 & $\begin{array}{l}\text { Grid reliance } \\
(\%)\end{array}$ & $\begin{array}{l}\text { Grid defection } \\
(\%)\end{array}$ & $\begin{array}{l}\text { Grid reliance } \\
\text { (PV baseline) }\end{array}$ & $\begin{array}{l}\text { Grid defection } \\
\text { (PV baseline) }\end{array}$ \\
\hline Load only & 2758 & 100 & 0 & na & na \\
With PV & 1652 & 60 & 40 & $100 \%$ & $0 \%$ \\
With PV & 522 & 19 & 81 & $32 \%$ & $68 \%$ \\
and DESS & & & & \\
\hline
\end{tabular}

Table 3. Josh's House value of exported PV energy - impact of DESS [8].

\begin{tabular}{llll}
\hline $\begin{array}{l}\text { Excess PV } \\
\text { production exported }\end{array}$ & $\begin{array}{l}\text { Export to grid } \\
\mathrm{kWh} / \text { year 2016 }\end{array}$ & $\begin{array}{l}\text { Value (based on } \\
\text { REBS } \$ 0.07125 / \mathrm{kWh})\end{array}$ & $\begin{array}{l}\text { Proportion of } \\
\text { PV exported } \\
\%\end{array}$ \\
\hline PV only & 3970 & $\$ 282.64$ & 78 \\
PV and DESS & 1092 & $\$ 77.75$ & 22 \\
\hline
\end{tabular}

Figure 2 illustrates the sensitivity of grid reliance to varying both PV sizing and storage capacity. The scenarios are based on a $5 \mathrm{~kW}$ inverter size. It indicates that, for the installed $8 \mathrm{kWh}$ DESS storage capacity, the point of inflexion is at approximately $3 \mathrm{kWp}$ array size, as per the existing system.

\subsection{Autonomy}

Being autonomous for electricity supply, or creating a "stand-alone" system, was never the intention of this project and, if adopted broadly, would undermine the electricity grid that supports much essential public infrastructure. But it is interesting to test what increase in system size would have been required to eliminate the need to import electricity from the grid during 2016. Even at the largest system size presented in Figure 2, with a PV array of $20 \mathrm{kWp}$ and a DESS capacity of $20 \mathrm{kWh}$, grid reliance remains at $6 \mathrm{kWh} /$ year for 2016 , or $0.2 \%$ of the total energy consumption for the year. This remaining import from the grid is spread over $14 \mathrm{~h}$ of the year, mainly in the winter months of May and June.

A pragmatic augmentation of this system, in terms of roof size and local regulations, would be to increase the PV array and inverter sizes both to $5 \mathrm{~kW}$, and to increase the DESS sizing to $20 \mathrm{kWh}$. This results in a modelled system that requires imports for just over $100 \mathrm{~h}$ of the year, importing $46 \mathrm{kWh}$, or $1.6 \%$ of total annual energy use. Realistically, this unmet load could be managed by the home's occupants given even rudimentary system information and alerts to assist decision making on use of appliances. Alternatively, or in concert, some degree of automated control of dispatchable loads would assist to achieve practical autonomy with this system sizing.

Increasing the DESS sizing to $30 \mathrm{kWh}$, while retaining the $5 \mathrm{~kW}$ PV array and inverter sizes, reduces the annual unmet load to $7 \mathrm{kWh}$, spread over $18 \mathrm{~h}$. This unmet load could certainly be managed by the home's occupants without resorting to importing energy. 


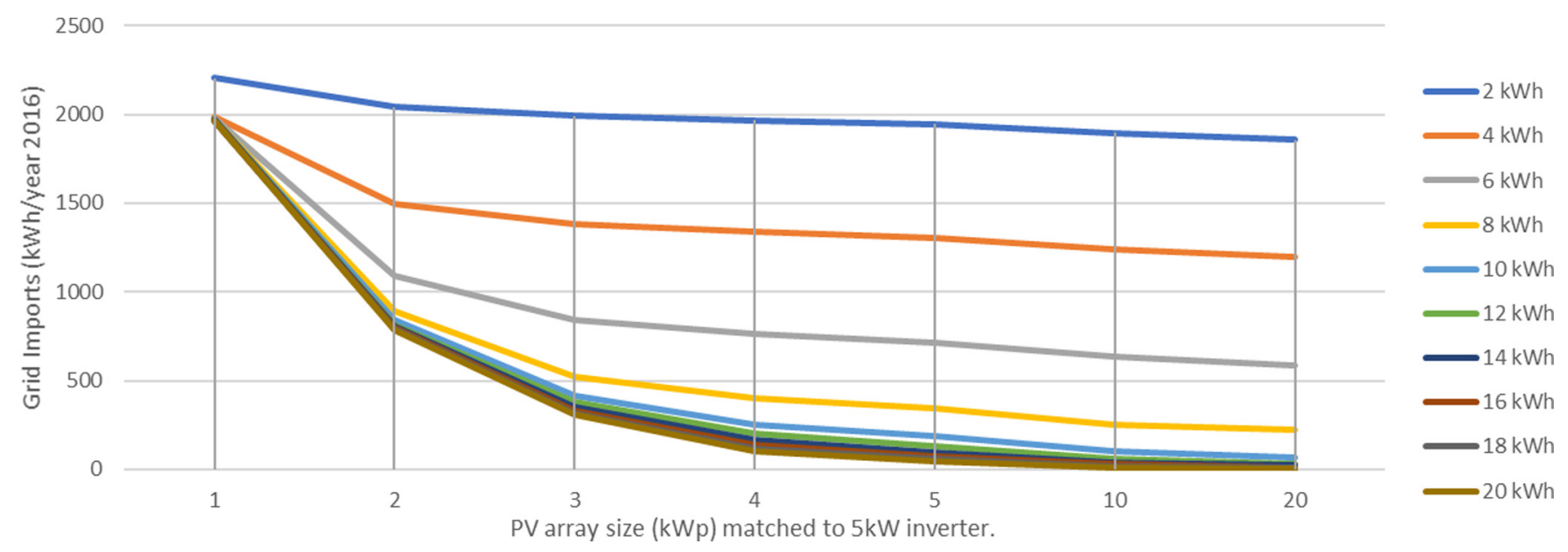

Fig. 2. Josh's House grid reliance - sensitivity to PV size for a range of DESS capacities $[9,10]$.

Table 4. Proposed modelling parameters and variables.

\begin{tabular}{lll}
\hline & Value & Comment \\
\hline Variables & & \\
DESS storage capacity & $10 \mathrm{kWh}$ & Existing \\
PV array size & $3 \mathrm{kWp}$ & Existing \\
PV inverter size & $2.5 \mathrm{~kW}$ & Existing \\
Load factor & 1 & No adjustment of load \\
& & \\
Parameters & $95 \%$ & As set in real system \\
Maximum depth of discharge & $95 \%$ & ${\text { Calculated from data } \text { set }^{\mathrm{a}}}_{\text {Discharge efficiency }}$ \\
Maximum discharge rate & $9 \mathrm{~kW}$ & Specification \\
Charging efficiency & $95 \%$ & Calculated from data set $^{\mathrm{a}}$ \\
DESS parasitic load & $182 \mathrm{~W}$ continuous & Established to create best match to observations \\
\hline
\end{tabular}

a The observed efficiency is a 90\% "round trip" efficiency. The charge/discharge efficiencies are set to give this combined result.

\subsection{Comparison to modelled predictions}

In order to understand the data, including implications that there may be for other systems, the chosen methodology has been to create a simple mathematical model that is tuned to replicate, to a certain degree, the observed data. System parameter values are then inferred from the model inputs that provide the best replication. The approach is informed by some understanding of the physical system and is tested against claimed system performance values, as well as observed data. The added benefit of this approach is that a model of this type of system is developed and can be tuned once data from other similar systems become available.

Parametric and variable values that give results that correlate with the observed data are listed in Table 4 . These values resulted in total grid reliance prediction that is within $6 \mathrm{kWh} /$ year (2016) of the observed data.

Figures 3 and 4 show the real data set of battery cycles for the year, followed by the modelled set.
Possible impacts on DESS performance that merit further investigation to improve the model include:

- ambient and DESS internal temperatures;

- rate of charging and discharging;

- battery behaviour at low levels of charge.

\subsection{Anomalies identified}

\subsubsection{Peak charging events}

The DESS is observed to be drawing large charging flows (approximately $8 \mathrm{~kW}$ ) for short periods $(<10 \mathrm{~min})$ during periods of very low battery SOC, mainly in winter months. This may be due to self-protection algorithm that tries to boost the battery if it has been a low level for a certain period. The peaks are far in excess of the concurrent PV production, and show in the grid metering as import peaks. Figure 5, which compares power flows as measured to the modelled flows, illustrates these charging peaks, which are not anticipated in the model. 


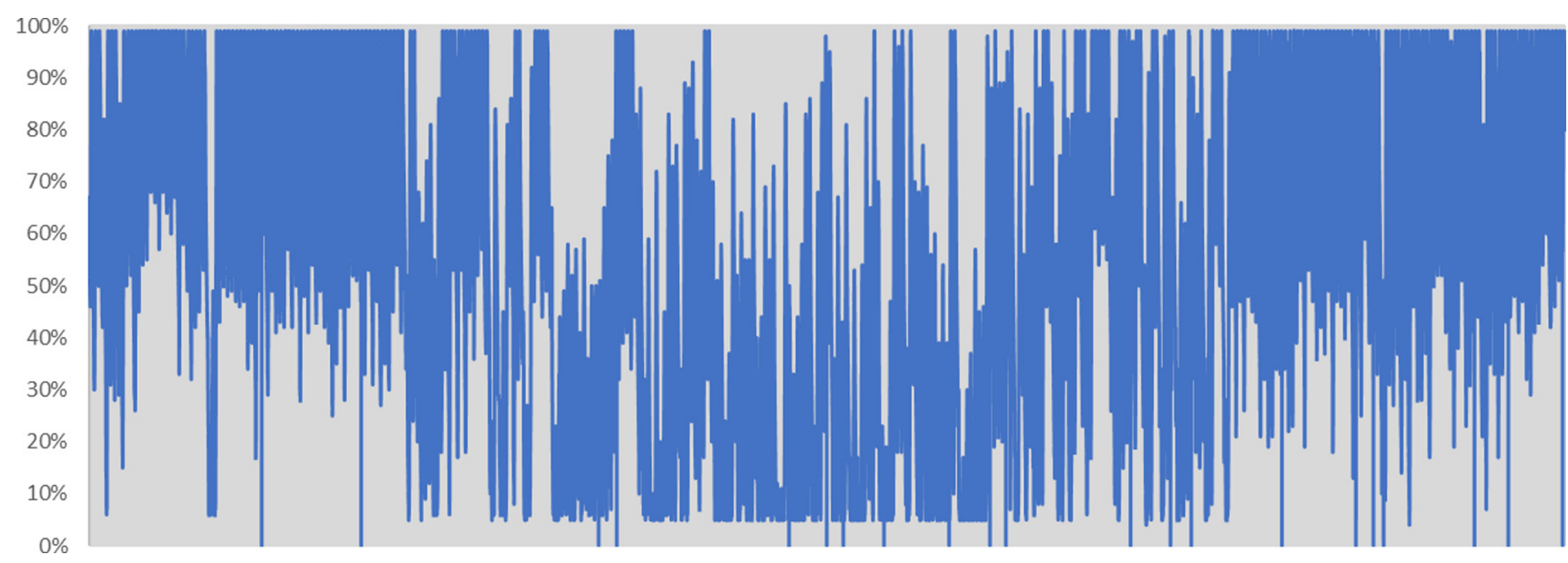

Fig. 3. DESS battery state of charge cycles over year 2016-observed data.

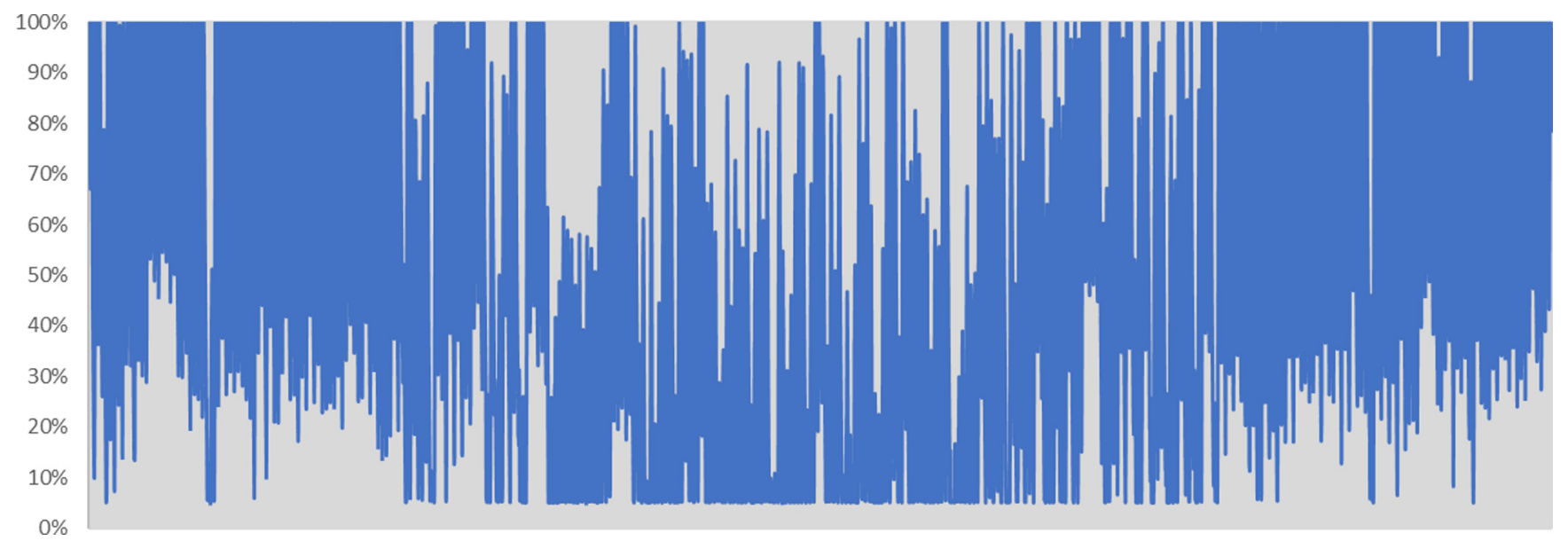

Fig. 4. DESS battery state of charge cycles over year 2016-modelled data.

\subsubsection{Efficiency and assumed parasitic load}

Energy flows into and out of the battery indicate an efficiency of around 90\%. However, energy is apparently being consumed outside of the metered elements and is represented in the model as a parasitic load equivalent to a continuous 182-W load. Table 5 indicates the efficiency implications of this loss and introduces the concept of "Effective Efficiency", which is defined as the ratio of reduced grid import to reduced solar export after the installation of the DESS.

\section{Conclusions}

Josh's House, and associated monitoring infrastructure, has provided an opportunity to observe the performance of a DESS of a type that, according to energy sector commentators [2,11-13], is likely to be installed throughout Australian electricity networks in the near future. The numerical observations are particular to this system but the anomalies and variations on anticipated performance provide some basis for analysing other DESS systems as they come on line in the domestic context.

\subsection{Lessons learned from the installation of the system}

- Physical protection of cabinets: Josh's Battery is installed in the carport. This offers a good combination of ventilation, shading, and weather protection, and is likely to be a common choice for domestic systems. However, the proximity to moving vehicles presents a risk of physical damage to the DESS cabinets and their contents. Bollards of other such physical barriers are being considered;

- Parasitic load: the DESS introduces a self-load that impacts the overall system performance and needs to be considered in modelling. In this case, the introduced load has not been identified directly but, using the model to emulate effect, is equivalent to an approximate $200 \mathrm{~W}$ continuous load;

- Control system algorithm: the DESS system appears to be introducing sporadic high load spikes that result in an import from the grid, in response to low state of battery charge. This may be a deliberate function of the DESS control system, or it may be a malfunction. A follow-up review of DESS output data by the installer, and tuning of the control system if any problematic behaviour is observed, is likely to reduce these occurrences; 


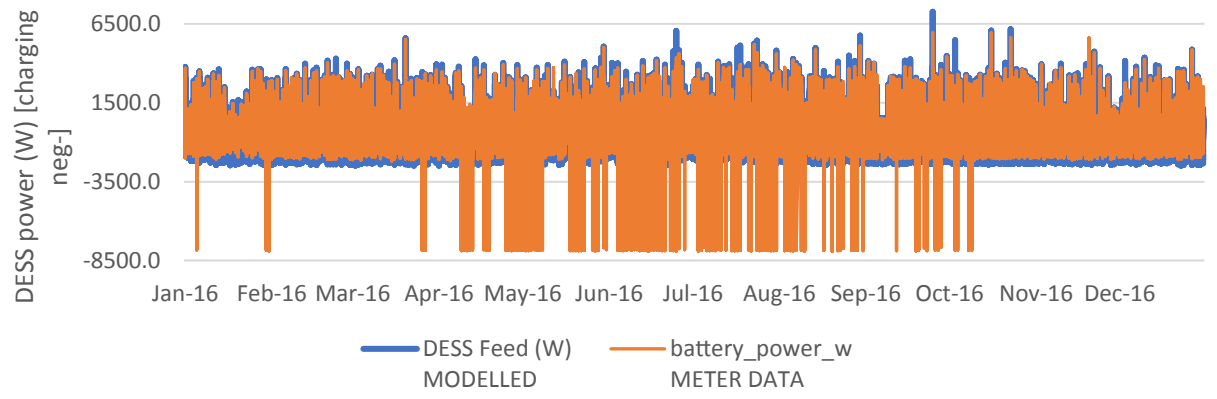

Fig. 5. Comparison of modelled vs. measured DESS power flows.

Table 5. Efficiency and effective efficiency.

\begin{tabular}{llllll}
\hline Total supply from battery (discharge) & 2555 & $\mathrm{kWh} /$ year 2016 & PV consumed by DESS & 2878 & $\mathrm{kWh} /$ year 2016 \\
Total load of battery (charging) & 2781 & $\mathrm{kWh} /$ year 2016 & Total load met by DESS & 1179 & $\mathrm{kWh} /$ year 2016 \\
Efficiency (annual average) & $92 \%$ & & Effective efficiency & $41 \%$ & \\
\hline
\end{tabular}

- Commissioning: now that the system anomalies have been identified, they can be rectified by engineers. However, this kind of analysis is unlikely to occur in every case. A robust standard for commissioning and ongoing monitoring of DESS systems to ensure performance and adherence to protocols should be developed. The importance of achieving consistent results, in line with realistic design expectations, increases as multiple systems interact with ever decreasing human intervention and oversight.

\subsection{Future research}

An additional layer of monitoring has recently been added to Josh's Battery, which is logging one-second interval data. These data will enable more detailed analysis of the ways that the DESS control system responds to changing conditions for a better understanding of network impacts and anomalies such as the charging load spikes that are identified in this paper.

The DESS manufacturer has been engaged to investigate the performance anomalies identified in this paper.

\section{References}

1. X. Luo, J. Wang, M. Dooner, J. Clarke, Overview of current development in electrical energy storage technologies and the application potential in power system operation, Appl. Energy 137, 511-536 (2015)

2. K. Worthmann, C.M. Kellett, P. Braun, L. Grüne, S.R. Weller, Distributed and decentralized control of residential energy systems incorporating battery storage, IEEE Trans. Smart Grid 6, 1914-1923 (2015)
3. G. Parkinson, Morgan Stanley sees 2.4 million Australia homes with battery storage (RenewEconomy, 2015) [Online], available at: http://reneweconomy.com.au/morgan-stanleysees-2-4m-australia-homes-with-battery-storage-20668/ (accessed on: 2017/03/02)

4. Australian Energy Regulator, Energy made easy - understand and compare your home electricity usage (2017) [Online], available at: https://www.energymadeeasy.gov. au/benchmark (accessed on: 2017/27/02)

5. C. Shearer, Off the grid, Aust. Sci. 36, 24 (2015)

6. S. Currie, Design a small-scale energy storage system for renewable energy, Doctoral dissertation, Charles Darwin University, 2016

7. Data Analysis Australia, Profiles of power (2016) [Online], http://www.daa.com.au/case-studies/profiles-of-power/ (accessed on: 2017/27/02)

8. Synergy, Solar credits, REBS \& upgrades (2017) [Online], https://www.synergy.net.au/Your-home/Help-and-advice/ Solar-credits-and-upgrades (accessed on: 2017/07/27)

9. Homer Energy, HomerPro (Homer Energy, 2017), available at: http://www.homerenergy.com/HOMER_pro.html (accessed 2017/07/02)

10. Natural Resources Canada, RETScreen (Government of Canada, 2017), available at: http://www.nrcan.gc.ca/ener gy/software-tools/7465 (accessed on: 2017/07/02)

11. H. Lewis, Lithium-ion battery consultation report (Helen Lewis Research, 2016), pp. 9-10

12. A. Macdonald-Smith, Australia primed as heartland for battery-storage revolution (2015) [Online], available at: http://www.smh.com.au/business/carbon-economy/ australia-primed-as-heartland-for-batterystorage-revolu tion-20150527-ghba6h.html (accessed on: 2017/03/02)

13. G. Parkinson, Lend Lease to pioneer large scale battery storage for new Perth suburb (RenewEconomy, 2016) [Online], available at: http://reneweconomy.com.au/lendlease-to-pioneer-large-scale-battery-storage-for-new-perthsuburb-17584/ (accessed on: 2017/03/02)

Cite this article as: Josh Byrne, Mark Taylor, Jemma Green, Josh's Battery - a more even relationship with the grid, Renew. Energy Environ. Sustain. 2, 37 (2017) 